\title{
Using the Motivation-Attributes-Skills-Knowledge Validation Model in Implementing Knowledge Management Strategies in Small and Midsize Employers (SME'S): A Theoretical Study
}

\author{
Jeff Stevens $^{1^{*}}$, PhD, Jim Chen ${ }^{2}$, PhD \\ ${ }^{1}$ Assistant Professor, McNeese State University, USA \\ ${ }^{2}$ Associate Professor, McNeese State University, USA
}

*Corresponding Author: Jeff Stevens, Assistant Professor, McNeese State University, USA

\begin{abstract}
Knowledge management (KM) program development has historically been a major obstacle for small and midsize enterprises (SMEs') to achieve. In this theoretical study, we illustrate how many SMEs struggle to develop knowledge management programs along with general knowledge transfers. Therefore, the authors will link the competency cluster validation model, the Motivations-Attributes-Skills-Knowledge Model (MASK), with the SMEs' knowledge management program development to address the challenges a SME faces in developing a KM program. The MASK is an upward focused, sequential competency validation model providing ease and speed of implementation for SMEs when developing a knowledge management program. The Motivations-Attributes-Skills-Knowledge Competency Cluster Validation Model (MASK) could successfully serve as a foundation and process for the construction of a knowledge management program in a SME. It also addresses the main challenges facing SME's as they struggle to develop knowledge management programs along with general knowledge transfers. This paper follows a format provided in A. T. Arikan's Interfirm Knowledge Exchanges and the Knowledge Exchanges Capability of Clusters (Arikan, 2009) in that it illustrates eight (8) proposal that could aid a SME in developing a knowledge management program. This theoretical study also followed the Critical Incident Technique (CIT) method as this methodology provides a productive practical framework for this theoretical study (Flanagan, 1954). This research outlines several proposals pertaining to each step in the MASK and how they serve as strong foundation for SME's to develop a KM program. Further, this theoretical study relates each step of the MASK and how it functions in developing a SME knowledge management.
\end{abstract}

Keywords: Small and Midsize Enterprise, Knowledge Management, Motivations, Attributes, Skills, Knowledge, Competency Clusters.

\section{INTRODUCTION}

Today's employees are exposed to more information in their work than any other time in history, which makes knowledge management (KM) a critical skill-set need for employees and a critical strategy for SME's. Employees in SME's, like those in large organizations, must be able to deploy knowledge management in their work or they will quickly reach a point of diminishing returns (Argote, 1999). However, SME's have generally struggled with developing a knowledge management program due mainly to their inability to consolidate knowledge management assets and the time needed to refine the knowledge into a viable knowledge management program (Arikan, 2009). This challenges a SMEs ability to realize the benefits of a knowledge management program or the time needed to carry out this concept. Over the past few decades, the concept of competency clusters has become popular and widespread in both theory and practice (Navickas \& Malakauskaite, 2009). Competency cluster modeling is quickly becoming the knowledge management development standard, as well as measurement and performance management standard for this century (Gaimon\& Bailey, 2013). However, knowledge management development efforts have not addressed the complicated process of competency cluster validation models for SME's to aid these types of organizations in developing their knowledge management programs. A major gap in literature exists related to the expansion of a defined process of developing comprehensive competency cluster validation models, specifically those related to SME knowledge management. This study will show that the MASK and knowledge management go hand-in-hand in putting SMEs in a much better position to manage the increasing amount of knowledge that these organizations are collecting on an 
Using the Motivation-Attributes-Skills-Knowledge Validation Model in Implementing Knowledge Management Strategies in Small and Midsize Employers (SME'S): A Theoretical Study

ongoing basis. The primary effort pertaining to competency cluster work and knowledge management development focuses on the most basic work skill activities that do little more than keep SME's compliant with various laws and little else (Mojibi, et.al, 2015).

If the SME takes the time to implement a knowledge management program by meeting specific goals that build on the competency cluster, the SME emerges in a much stronger position to meet their keep objectives. The major purpose of this theoretical study will focus on the introduction of the MASK as it relates to developing knowledge management strategies in SME's. This model will allow SME's to review the knowledge management aspects they possess to understand what is needed by them to develop a comprehensive knowledge management program. This theoretical study will also provide a component driven process for SME's to compartmentalize their knowledge management. It also links a set of competencies into a cluster with a need in each component to develop a knowledge management program that best fits their needs. The model will also allow these types of organizations to use knowledge management as a competitive advantage and in some cases, to enhance their very survival. The last key purpose of this theoretical study will be to utilize this model to illustrate the importance of knowledge management to SME's, which has typically been utilized in a haphazard manner or not at all by these types of organizations (Mojibi, et.al, 2015). The development of a theoretical framework related to the implications of the MASK characteristics on the knowledge management in SME's will be one of the critical aspects of this study. It also focuses on the identification of a competency cluster validation model in aiding SME's to address the knowledge management challenge and exploiting knowledge management opportunities for SME's and will also provide a vision related to the current activities being undertaken, with regard to competency clustering, by the SME sector (Brahma \& Mishra, 2016). Last, this theoretical study ascribes to the premise that the MASK is a competency cluster validation model that exceeds traditional competency cluster models, such as the knowledge-skills-ability (KSA) in addressing knowledge management challenges \& opportunities (Gonzalez, \& Martins, 2014). In this aspect, the study will illustrate the specific steps in the MASK as they pertain to addressing specific SME knowledge management competency clusters. The present study investigates a specific and challenging managerial activity, which is the role of the competency cluster knowledge management (Lippert \&Gaáil, 2014). Lastly, the MASK provides a balance of qualitative and quantitative factors in addressing the SME KM (Stevens, 2005)

\section{ReVIEW OF THE Literature AND Propositions}

Knowledge management has become a critical need within SMEs. Knowledge management is typically defined as a discipline that promotes an integrated approach to identifying, capturing, evaluating, retrieving, and sharing all of a company's information assets (Vivas, et.al 2016). The importance of knowledge management for the SME venture is evident, as differences in performance are driven by differences in knowledge levels and requirements (Wiklund\& Shepherd, 2003). Without a productive knowledge management program, the effort of knowledge transfer and development will be severely inhibited. The requirements for successful implementation of knowledge management include gaining a complete understanding of the relevant business culture through the different levels of the organizational hierarchy, as well as identifying vital factors for success (Ward, 2004). The SME decides between proceeding with or abandoning an opportunity, or investing further in knowledge acquisition through managing information about the attractiveness of an opportunity (Tubigi\&Alshawi, 2015). This becomes a demarcation point for the SME as to whether they pursue a knowledge management program. Obstacles or constraints to attempts to constitute knowledge as an organizational resource have been previously dealt with in the context of organizational learning perspectives; however, there still remain barriers toward making learning available and all-pervasive throughout organizations (Lippard \&Gaail, 2014). It is reasonable to value knowledge in financial or economic terms; it is also important to consider the problems which make it difficult to extract and transfer knowledge within specific organizational settings (Jain \& Moreno, 2015). Gagne (1962) argues that procedural material should be organized into a series of sequential steps that should be analyzed and divided into subunits (Argote, 1999).

The work by Gagne and other pioneers in this field provided the foundation for both the study of competency clusters as well as knowledge management (Argote, 1999). Yet most of their work and the work of others within these areas have focused mainly on basic trade skill competencies and large 
Using the Motivation-Attributes-Skills-Knowledge Validation Model in Implementing Knowledge Management Strategies in Small and Midsize Employers (SME'S): A Theoretical Study

organizations as opposed to SMEs (Brown, Bruno, \& Cooper 2012). Within the series of sequential competency cluster steps in which competencies are mastered, the employees must master each step before the entire procedure is undertaken and thus validated as per the MASK process. Therefore, the competency cluster could play an important role here. If the SME takes the time to implement a knowledge management program by meeting specific goals that build on the competency cluster, the SME emerges in a much stronger position to meet their critical objectives Current competency cluster modeling and knowledge management efforts focus heavily upon processes and systems as they pertain to rudimentary skills along with basic job skills (Dubois, 1993). However, knowledge management requires competency assessments that go beyond elementary skills and involve more advanced skills, especially in today's workplace and the future workplace. As mentioned previously in this theoretical study, the MASK is a sequentially driven process that involves mastering competencies in each step. These competencies are then clustered to address the targeted competency cluster. The first step in the MASK is the environmental scan in which the external and internal environments related to the SME are examined as it relates to the identified competency cluster(s) needed to aid SMEs in developing a knowledge management program. Environmental scanning is a process of identifying trends that are most likely to impact the knowledge management components within a SME (Mojibi, et.al, 2015). A critical component in developing the environment scan of the MASK is scanning both internal environment and external environments. The means by which organizations gather information on changing environmental conditions is a critical aspect related to developing a viable environmental scan process (Baron \& Ensley, 2006). This step provides a foundation for the MASK's ability to further the SME's knowledge management process as the environments are scanned to benefit the subsequent opportunity recognition emerging from this model. Once the SME adequately identifies trends, through environmental scanning, it can craft a strategy that will help them address the changes related to knowledge management (Tubigi\&Alshawi, 2015). Developing the needs assessment requires the SME to incorporate the trends and observations collected through the environmental scan into a process where it serves as a vital step in the MASK and addressing the SME knowledge management competency cluster. The needs assessment step is followed by the motivation, attributes, skills and knowledge steps that create the desired competency cluster, which in this case is a SME KM program.

\subsection{Environmental Scan}

Proposition 1 - Environmental Scan: The appropriate use of an internal and external environmental scan creates more opportunities to develop subsequent steps of the competency cluster model validation related to knowledge management in a SME. The stronger the environmental scan, the more reliable this model becomes as critical external and internal factors are identified. The correct use of internal and external environmental scans will allow a researcher to identify a strong set of competencies needed to refine a more robust competency cluster. The wider the breadth of environmental scanning related to the knowledge management is required in the building of a foundation to develop this model.

Environmental scanning is an organization's insightful monitoring of its external and internal environments. By undertaking this monitoring effort, an organization can generally detect early signs of threats, opportunities and other items that may influence its current and future plans (Cope, 2005). Among the key of aspects environmental scanning related to the MASK is the fitness for use, which typically allows the information to be logical, doable, actionable and timely. This provides the parameters needed to put the SME in position to build off this step in the model regarding its fitness for use information in a SME KM. In this step in the model, the SME must continuously scan its external and external to looking for new possibilities. It aides the SME to identify the trends that are most likely to directly affect the SME (Robles, 2016). The first aspect that must be dealt with in an environment scan is to set some parameters on the type of the environmental scanning process. Ideally, the process will be able to devise a cause-and-effect process related to key findings that can be processed through the environmental scan (Cope, 2013). Along with identifying possible trends and refining possibilities, the environmental scan should allow the MASK to create strategies that will help SME to take advantage of inevitable changes that will confront it in the future. This step in the MASK should allow the SME to further devise the competency cluster strategies and allowing the model to be agile in developing the rest of the model. 
Using the Motivation-Attributes-Skills-Knowledge Validation Model in Implementing Knowledge Management Strategies in Small and Midsize Employers (SME'S): A Theoretical Study

\subsection{Needs Assessment}

Proposition 2: Needs Assessment - The higher the degree of the needs assessment components related to the knowledge management process allows for the critical aspects that characterize a competency cluster to be clearly identified as in need of action. In identifying these competencies, they continue to build on the target competency cluster. By undertaking a successful needs assessment, the more opportunities arise for the continued development of the competency cluster and future direction to address the knowledge management needs within the MASK.

A needs assessment is a systematic process for determining and addressing needs, or "gaps" between current conditions and desired conditions or "wants" (Shane \& Eckhardt 2005). In the case of knowledge management, it focuses on the discrepancy between the current knowledge collection competency and the desired knowledge management condition, which must be measured to appropriately identify the need (Taylor, 2015). The need can be a desire to improve current performance or to correct a deficiency among other knowledge management needs in a SME through identifying competencies to aid in constructing a KM competency cluster (Baron and Ensley, 2006). The needs assessment can be an effective tool to clarify challenges and identify appropriate interventions and/or solutions to address potential infinite needs to put SME's in a better position to develop and manage an efficient KM competency cluster program. By clearly identifying the challenges or opportunities, finite resources can be directed towards developing and implementing a feasible and applicable knowledge management solution (Mojibi, et.al, 2015). Gathering appropriate and sufficient knowledge competency informs the process of developing an effective product that will address the SME knowledge management competency. Needs assessments are only effective when they are ends-focused and provide evidence that can be used to determine which of the possible means-to-the-ends are most effective and efficient for achieving the desired knowledge management results (Irwin, 2008). There are many tools to gather information about employee performance that can work best in different circumstances in building the SME knowledge management competency cluster. Needs assessments generally evaluate the level of organizational performance as it relates to what a SME needs to address in the development of a knowledge management program (Acs, et.al. 2009). The needs assessment examines the motivations, attribute, skills, and knowledge competencies required for effective SME knowledge management (Stevens, 2005). The assessment analyzes how well an individual employee is doing a job and determines the individual's capacity to do new or different work (Hauser, 2014). Individual assessments provide information on which to build and manage a SME KM program. The needs assessment aspect of the MASK is assessing the right information, combined with the right adaptations, to determine the critical next step in the model, which is the task analysis, to better provide the SME future viability as it relates to knowledge management program in an SME through competency clusters (DiPasquale \&McInerney 2010).

\subsection{Task Analysis}

Proposition 3: Task Analysis - The task analysis step presents specific competencies that need to be addressed to construct the SME knowledge management program. It also creates a positive relationship link between the needs assessment and the motivational steps in the MASK in relation to moving from the pre-work aspects to the action steps in the MASK as it relates to further constructing the SME knowledge management program through a competency cluster process.

The task analysis aspect of the MASK builds off of the needs assessment that is achieved in the second step of the MASK (Stevens, 2011). Tasks may be identified and defined at multiple levels of abstraction as required to support the purpose of the analysis. Task analysis focuses on the examination of how a task is accomplished, including a detailed description of activities, task and element durations, task frequency, task allocation, task complexity, environmental conditions, and any other unique factors involved in or required for one or more people to perform a given task (Tubigi\&Alshawi, 2015). Task analysis is a hierarchical representation of what steps it takes to perform a task for which there is a goal and for which there is some lowest-level "action" or interaction among humans and/or machines (Mojibi, et.al, 2015). A knowledge management task analysis, for example, is an analysis of SME performance requirements which, if not accomplished in accordance with system requirements, will likely have a negative impact on the SME knowledge management program. Task analysis may be comprised of specific tasks and be analyzed as time 
Using the Motivation-Attributes-Skills-Knowledge Validation Model in Implementing Knowledge Management Strategies in Small and Midsize Employers (SME'S): A Theoretical Study

motion studies, among other measurement processes, along with other types of work-related core competencies (Hetzner\& Gruber, 2015). The knowledge management task analysis is applied to modern work environments, such as intellectual capital and other modern knowledge management work related tasks where less manual work occurs as opposed to the knowledge worker environment.

\subsection{Motivation}

Proposition 4: Motivation - The motivation step encompasses the amount of drive that will be deployed by the SME in developing competencies and maintaining the competency cluster driven knowledge management program. As the MASK transitions from the pre-work stage to the action stage, this step creates the environment to create an effective knowledge management program. Motivating change is a critical aspect in this step of the MASK as it allows for logical risk taking to drive effectiveness of the knowledge management program. Motivation within the MASK develops the modality for activating the knowledge management program within a SME. The more SME's can cluster motivational competencies to follow the needs assessment and task-analysis steps, the more opportunities arise within the model to develop the subsequent steps in the MASK competency cluster.

The motivation step is the first step in the action section; the fourth step in the model; and the first step in the application aspect in the creation of the MASK of a SME knowledge management program, which compels one to action and provides an application foundation for the other application steps (Figure-1). According to the research, motivation has rarely been formally implemented into a competency cluster model as is the case with the MASK (Chatterjee, 2014). Typically research in this area has focused on knowledge, skills and abilities (KSA's) (Sorenson, Rivkin \& Fleming, 2006). KSA's are more suited to the workforce of the past and does not take into consideration the new dynamics of the workplace of today in which qualitative factors play a larger role. The MASK allows for the important qualitative factors to become an integral part of the competency cluster process. They are placed at the front end of the MASK to provide a foundation based on the unique challenge they pose. Without successfully employing these steps, a competency cluster related to a SME knowledge management cannot successfully be developed (Stevens, 2011). This is based on the premise that qualitative factors are more difficult to measure and manage than are quantitative factors. The MASK asserts that motivation is the pathway to developing a fully integrated and functional competency cluster validation to meet the demands of the SME knowledge management. Motivation can be developed as a source of energy influencing the workplace and drives the SME knowledge management program (Chatterjee, 2014).

Table1. Motivations

\begin{tabular}{|l|l|l|}
\hline \multicolumn{1}{|c|}{ Author } & \multicolumn{1}{|c|}{ Summary } & \multicolumn{1}{|c|}{ Impact on SME's } \\
\hline $\begin{array}{l}\text { Hetzner, } \\
\text { Helmut, and } \\
\text { Gruber, 2015 }\end{array}$ & $\begin{array}{l}\text { Personal initiative and self-efficacy } \\
\text { significantly positively affect reflection at } \\
\text { work. }\end{array}$ & $\begin{array}{l}\text { Increases the impact of a productive } \\
\text { environment for developing a KM program } \\
\text { characterized by interpersonal trust, mutual } \\
\text { respect \& supportive cooperation. }\end{array}$ \\
\hline $\begin{array}{l}\text { Vanthournout, } \\
\text { et al. }\end{array}$ & $\begin{array}{l}\text { The climate typically links KM and process } \\
\text { organizations driving employee motivation. }\end{array}$ & $\begin{array}{l}\text { The SME should mediate the link between } \\
\text { good KM and organizing management. }\end{array}$ \\
\hline Taylor, 2015 & $\begin{array}{l}\text { There is a relationship between people and } \\
\text { their work environment that affects } \\
\text { motivationto work and perform. }\end{array}$ & $\begin{array}{l}\text { The potential for change in motivation should } \\
\text { take place in the work environment and } \\
\text { nurturing this premise in the development of the } \\
\text { KM. }\end{array}$ \\
\hline $\begin{array}{l}\text { Seemann \& } \\
\text { Seemann, 2015 }\end{array}$ & $\begin{array}{l}\text { Motivation can help to increase satisfaction } \\
\text { and achievements of employees and thus } \\
\text { boost the effectiveness of organizations. }\end{array}$ & $\begin{array}{l}\text { A critical factor in the development of the } \\
\text { KM is related to organizational effectiveness } \\
\text { that drives organizing knowledge for SME's. }\end{array}$ \\
\hline
\end{tabular}

The process of motivation is derived from the enjoyment of knowledge competency collection in the development of a SME knowledge management program where the process itself acts as the incentive (Hauser, 2014). The SME knowledge management program must be able to motivate employees to make them meet the requirements in terms of qualification and professional experience, attitude towards work and deploying the SME knowledge management program. Motivation also targets the energy and enthusiasm (compelling to action) of people on knowledge management program competency cluster (Navickas\&Malakauskaite, 2009). It has not only the role of determining people to work, but has also the property to determine them to perform their work as well, which requires 
optimum exploitation of physical and intellectual resources of employees (Stevens, 2011). The aim of this level of the research is to reveal the motivation of cluster operations and to demonstrate the importance of the knowledge management in the efficient and sustainable operations throughout an SME (Lippert \&Gaáil, 2014). The motivation step is a key action for developing a fully integrated and functional competency cluster validation to meet the demands of today's world of work. Motivation plays a crucial role of determining people to work as well as compelling optimal exploitation of physical and intellectual resources in developing the competency cluster model related to SME knowledge management competency cluster model.

\subsection{Attributes}

Proposition 5: Attributes - Attributes are a key factor in creating relationships related to the MASK and thus the development of the SME knowledge management program. They also encompass the challenges that stress and value-added aspects created for the SME knowledge management program. By leveraging attribute competencies, the SME can create the norms, and thus the culture that will be found in their knowledge management competency cluster program. The same attributes found within a competency cluster, the more opportunities arise for the qualitative knowledge management program to consolidate and advance the quantitative steps to drive the overall SME knowledge management competency cluster validation model.

Table2. Attributes

\begin{tabular}{|c|c|c|}
\hline Author & Summary & Impact on SME's \\
\hline Marlow, 2016 & $\begin{array}{l}\text { Exploring attributes and behaviors that } \\
\text { can develop relationships intended to } \\
\text { better understand how a KM program } \\
\text { works in an organization. }\end{array}$ & $\begin{array}{l}\text { Attributes and behaviors drive relationships } \\
\text { are intended to uncover the manner in which } \\
\text { KM can be leveraged to facilitate effective } \\
\text { work. }\end{array}$ \\
\hline $\begin{array}{l}\text { Sackett \& Walmsley, } \\
2014\end{array}$ & $\begin{array}{l}\text { Attributes such as conscientiousness } \\
\text { and agreeableness are important for } \\
\text { success across many jobs. }\end{array}$ & $\begin{array}{l}\text { The degree to which employees in SME's } \\
\text { can deal with stress, environmental factors, } \\
\text { and interact positively with coworkers and } \\
\text { customers. }\end{array}$ \\
\hline $\begin{array}{l}\text { Raver, Ehrhart \& } \\
\text { Chadwick, } 2016\end{array}$ & $\begin{array}{l}\text { Examines the antecedents of } \\
\text { organizational citizenship behavior } \\
\text { helping norms in SME's, specifically } \\
\text { with regard to how members' } \\
\text { personality, values, and beliefs predict } \\
\text { the emergence of helping norms. }\end{array}$ & $\begin{array}{l}\text { How helping norms are influenced by } \\
\text { having at least one member with various } \\
\text { levels of attributes that may influence } \\
\text { helping-norm development such as those } \\
\text { related to conscientiousness, agreeableness, } \\
\text { other oriented values, personal helping } \\
\text { beliefs can aide an SME. }\end{array}$ \\
\hline $\begin{array}{l}\text { Lee, To, \& Billy, } \\
2013\end{array}$ & $\begin{array}{l}\text { Attributepatterns and their associated } \\
\text { performance levels were examined } \\
\text { including team use, organizational } \\
\text { support, clear goals, collaborative } \\
\text { climate, coercive influence and } \\
\text { adaptation difficulty. }\end{array}$ & $\begin{array}{l}\text { Different attributepatterns achieved } \\
\text { markedly different levels of performance, } \\
\text { which provides learning opportunities within } \\
\text { SME's. }\end{array}$ \\
\hline
\end{tabular}

This study advances the idea that identifiable individual attributes determine, in part, the meaning one attaches to work (Shea, Van Fossen \&Vredenburgh, 2014). The measurement and assessment of attributes is focused upon the various properties, qualities, and characteristics needed to successfully negotiate the MASK process. This aspect of the MASK should encompass past aspects of quasicompetency cluster models, which are terms such as attitude, values, integrity, qualities, principles, maturity, accountability, etc. (Prasad \& Tran, 2016). They internalize the values and mission of the organization or competencies, such as personality of the employees, job satisfaction levels, and organizational culture - all such competencies which could have influenced their knowledge management in MASK (Bryson, 2016). Through the research pertaining to the development of the MASK, findings support that attributes generally encompass non-technical, value-added aspects of competency cluster mastery (Brown, Bruno \& Cooper, 2012). The attribute levels expand and add to the motivation aspects of the MASK in that it brings value-added competencies to a cultural and work environment. Work attributes enjoyment refers to the level of pleasure derived from work (Shea-Van Fossen \&Vredenburgh, 2014). Similarly, many theories, such as Vroom's (1964) expectancy theory, derive from an individually focused view that suggests that rational self-interest drives work 
Using the Motivation-Attributes-Skills-Knowledge Validation Model in Implementing Knowledge Management Strategies in Small and Midsize Employers (SME'S): A Theoretical Study

behaviors as individuals pursue goals that maximize one's utility, based on rational calculation (Dipasqaule\&McInerey, 2010). This attribute level allows the researcher to take information ascertained within the previous components as well as such aspects, abilities, etc. and further refine them to meet the KM competency cluster objectives. The participating SME's provided the evidence related to the assessment and/or implementation of attributes within their competency clustering efforts. Factors such as personality of the employees, job satisfaction levels, and organizational culture will drive this level of the study (Irwin, 2008). Rational self-interest attributes drive work behaviors as individuals pursue goals that maximize one's utility based on rational calculation, which also has a significant impact on this level of the study.

\subsection{Skills}

Proposition 6: Skills - The skills step focuses on both hard and soft skills, which are often limited in scope in these types of KM activities. The component of the skills associated with the opportunities for SME knowledge management are directly linked to the competency cluster objectives and are a quantifiable component in this model. Skills exchanged within the competency cluster creates a more positive relationship between the number of opportunities for knowledge exchanges and the collective skill exchanges within the competency cluster validation model.

Table3. Skills

\begin{tabular}{|c|c|c|}
\hline Author & Summary & Impact on SME's \\
\hline Robles, 2012 & $\begin{array}{l}\text { Hard skills are the technical expertise and } \\
\text { knowledge needed for a job. Soft skills are } \\
\text { interpersonal qualities, also known as } \\
\text { people skills, and personal attributes that } \\
\text { one possesses. }\end{array}$ & $\begin{array}{l}\text { While both types of skills are critical to a } \\
\text { SME's success, too often they focus on hard } \\
\text { skills. Yet soft skills like integrity, communica } \\
\text { tion, courtesy, responsibility, social skills, } \\
\text { positive attitude, professionalism, flexibility, } \\
\text { teamwork, and work ethic are as critical as hard } \\
\text { skills for a SME. }\end{array}$ \\
\hline $\begin{array}{l}\text { Prasad \& Tran, } \\
2013\end{array}$ & $\begin{array}{l}\text { Studied worker's incentives to invest in } \\
\text { nonverifiable skills related tothe context of } \\
\text { recent innovative work practices, where } \\
\text { jobs have become more flexible. The } \\
\text { article suggests an alternative approach: } \\
\text { firms promote workers only when they } \\
\text { acquire both firm specific skills and } \\
\text { general skills. }\end{array}$ & $\begin{array}{l}\text { This scheme reveals information about the } \\
\text { generalskill to competing firms, which in } \\
\text { turn allows the firm to credibly reward firm } \\
\text { specific skills within the SME. Further, } \\
\text { SME's have an incentive to pay for general } \\
\text { training to induce firm specific skills and } \\
\text { they are more likely to pay for it when jobs } \\
\text { are flexible. }\end{array}$ \\
\hline $\begin{array}{l}\text { Gould } \quad \& \\
\text { Schoonover, } \\
2009\end{array}$ & $\begin{array}{l}\text { Business leaders indicate they need workers } \\
\text { with higher levels of skills than those of } \\
\text { current employees. These skills include the } \\
\text { ability to communicate, reason, problem } \\
\text { solve, make decisions, function within a team } \\
\text { format, and become leaders. Creative and } \\
\text { critical thinking are included within all of } \\
\text { these skills. }\end{array}$ & $\begin{array}{l}\text { SME's can provide enrichment experiences } \\
\text { that focus on creative and critical thinking } \\
\text { within the work environment. Several } \\
\text { creative problem solving programs can be } \\
\text { incorporated into internal training programs } \\
\text { providing the opportunity to learn and } \\
\text { practice work place skills }\end{array}$ \\
\hline Bryson, 2015 & $\begin{array}{l}\text { This article argues that a focus on human } \\
\text { capability and its development can be used } \\
\text { to rethink the high skills policy visions } \\
\text { over recent decades. }\end{array}$ & $\begin{array}{l}\text { Human capability conceptions encourage a } \\
\text { more holistic appreciation and systemic } \\
\text { analysis of the impact of social arrangements } \\
\text { nomic structures on people's opportunity to } \\
\text { flourish at work, and in life. The holistic } \\
\text { approach to skill development allows the } \\
\text { SME to better develop and manage a KM } \\
\text { program. }\end{array}$ \\
\hline
\end{tabular}

The skills level is the sixth level of the MASK and involves the knowledge management tools that drive the process that the MASK focuses upon pertaining to the quantifiable mastery related to a specified competency cluster. Jain \& Moreno, (2015) define skills as application capabilities required to accomplish a particular set of skill-based objectives. Today's workers deal with a significant amount of information apparatus and, thus, skills should focus on these types of skill sets. In the case of the SME knowledge management, skills are measured in hard data, such as the ability to operate a 
specific type of knowledge apparatus (Prasad \& Tran, 2016). However, today's workplace goes well beyond basic skills and apparatus operation to those related to knowledge and critical thinking, among others that address today's SME work management requirements and needs. This aspect of the MASK is the most often utilized and measured with regard to a SME's competency cluster process. While this aspect of the MASK seems to be the quickest and easiest aspect to implement and measure, unless adequately focused, it does not provide an all-inclusive and successful competency cluster model. Further, while skills can often be obtained for the other aspects of the MASK, they must be included so as to drive a successful competency cluster process, because they are the set of skillsbased objectives that are utilized and measured as part of the SME knowledge management program. The knowledge management data is then refined and moved upward to the skills level of the MASK to address the knowledge step of the MASK. The importance of building absorptive capacity to facilitate skills transfer from external sources is critical in this step of the MASK (Cohen \& Levinthal, 1990). In particular, skills are acquired to assess the value of the opportunity and determine whether it should be pursued or abandoned, which defines how this steps fit within the MASK. Ward (2004) showed that skills may limit a person's views and thereby inhibit creativity along with more comprehensive skills required for a successful SME knowledge management program. However, the overall parameters of the MASK allow for creativity to become a critical aspect of the SME knowledge management program. Shane and Bailey (2013) considered the circumstances that made it more likely for a person to pursue an opportunity based on the discovery of a new skill. By adopting the skill-based view of the firm, a fundamental shift in operational skills becomes embedded in the SME knowledge management program including procedures and processes (Gaimon, 2008).

\subsection{Knowledge}

Proposition 7: Knowledge - Knowledge is the logical conclusion of the competency cluster model. Knowledge allows for the various steps in the model to flow through sequential processes and serves as the last step in validating the various competencies as a part of the targeted competency cluster. The higher the level of cooperative and systematic processes, the stronger the positive relationship between the number of opportunities for knowledge management exchanges and the number of validated exchanges within the competency cluster. Knowledge develops concepts and processes to create a modality that combines all the previous steps to create a climate conducive for meeting the competency cluster objectives and thus, a SME knowledge management program.

In the MASK knowledge phase, knowledge is acquired to enable the SME to effectively undertake decision making under uncertainty to the SME knowledge management framework and thus process the previous MASK. Dynamic learning perspectives of SME employees to understand how knowledge management activities change throughout the MASK phases of the program's life cycle occur. Knowledge is a key driver of SME alertness and creativity, both of which impact the quality and quantity of opportunities and innovations discovered (Gaimon\& Bailey, 2013). This phase explores the challenges of managing knowledge during the development of the product or technology, including the trade-off between exploration and exploitation. A critical component of this step in the MASK is the knowledge development and transfer, which focuses on the trade-off between exploration and exploitation of knowledge (Acs, et. al, 2009). The knowledge phase of the MASK process enhances efficiency and effectiveness of the knowledge management processes. Understanding the knowledge phase of the MASK and, thus the SME knowledge management competency cluster, allows for innovation and creativity to enhance both the model and the SME KM strategies. It will also allow for the measurement of the impact related to the quality and quantity of knowledge opportunities and innovations discovered within the model (Mojibi, et.al, 2015). The final key to this phase of the MASK will be to explore the challenges of managing knowledge and the transfer of the knowledge in the development of the model along with the SME knowledge management. SMEs will generally form the MASK competency cluster process in order to learn from their knowledge experience. Knowledge serves as the foundation for the SME knowledge management program as well as the final step to validate the competency cluster (Navickas\&Malakauskaitè, 2009). 
Using the Motivation-Attributes-Skills-Knowledge Validation Model in Implementing Knowledge Management Strategies in Small and Midsize Employers (SME'S): A Theoretical Study

Table4. Knowledge

\begin{tabular}{|l|l|l|}
\hline \multicolumn{1}{|c|}{ Author } & \multicolumn{1}{|c|}{ Summary } & \multicolumn{1}{|c|}{ Impact on SME's } \\
\hline $\begin{array}{l}\text { Sobreiro\&Claudino, } \\
2014\end{array}$ & $\begin{array}{l}\text { The study identified advantages in the use } \\
\text { of knowledge concepts in complex process } \\
\text { models and in classifying the knowledge } \\
\text { used in decisions. This could facilitate the } \\
\text { definition of training actions articulated with } \\
\text { the organization real needs. }\end{array}$ & $\begin{array}{l}\text { Affords the systematization of the } \\
\text { business processes related to the } \\
\text { structured work and the use of } \\
\text { knowledge management concepts in the } \\
\text { exception handling of the KM } \\
\text { processes. }\end{array}$ \\
\hline $\begin{array}{l}\text { Vanthournout, et. } \\
\text { al, 2014 }\end{array}$ & $\begin{array}{l}\text { Explored the role of motivation as a } \\
\text { mediating factor between workplace } \\
\text { climate factors and knowledge acquisition } \\
\text { in modern organizations. It also } \\
\text { investigated the direct and indirect links } \\
\text { between perceptions of the workplace } \\
\text { climate, motivation to gain knowledge } \\
\text { and approaches to KM in the workplace. }\end{array}$ & $\begin{array}{l}\text { Both workplace climate factors and } \\
\text { approaches to knowledge acquisition } \\
\text { and management. }\end{array}$ \\
\hline $\begin{array}{l}\text { Lin, Chen, Hsu, \& } \\
\text { Fu, 2015 }\end{array}$ & $\begin{array}{l}\text { Illustrates knowledge as an intensive task } \\
\text { related to both the worker and the } \\
\text { enterprise. It also showed that problem } \\
\text { solving competence is largely determined } \\
\text { whether the members can effectively } \\
\text { utilize knowledge resources. }\end{array}$ & $\begin{array}{l}\text { Having complement knowledge, } \\
\text { allocating knowledge in right position, } \\
\text { and knowing the allocation of resources } \\
\text { are critical for SME KM success. }\end{array}$ \\
\hline Weinberg, 2015 & $\begin{array}{l}\text { Presented a knowledge-sharing model that } \\
\text { explains individual members' motivation to } \\
\text { share knowledge across the enterprise. }\end{array}$ & $\begin{array}{l}\text { Kemonstrates how beliefs in the SME } \\
\text { KM can stimulate one's intrinsic desire to } \\
\text { engage in knowledge-sharing behaviors. }\end{array}$ \\
\hline
\end{tabular}

\subsection{Competency Clusters}

Proposition 8: Competency Clusters - This step in the MASK links the steps and identified clusters within the MASK and the objectives put forth in the competency cluster. It is critical that the objectives set forth in the competency cluster and those identified in the MASK allow the SME knowledge management program to meet the expected outcomes. By linking the critical competencies to create a competency cluster, it allows for a more focused assessment and development of the critical factors in a SME knowledge management program. The competency cluster step also reaffirms the MASK modality in addressing the SME knowledge management program. In summation, the competency cluster is the objectivity of the MASK as it relates to clustering specified competencies into knowledge management program for a SME.

The last major significant factor of this study pertains to its sequential competency cluster validation, which in this case is the development of a KM for the SME. When the phases within the identified competency cluster concludes, there is significant uncertainty about the true value of the opportunity (Baron and Ensley, 2006). Determinant factors of cluster success have been identified by using competency cluster factors, such as the operational activity of the cluster, as well as the satisfaction of the members in the field of innovation and productivity (Lippert \&Gaáil, 2014). Mapping the competency factors that have been developed within the MASK framework to develop effective competency clusters allows for the MASK to follow a defined sequential process. Thus, the competencies link together through the sequential process in order to mutually support their specific aspects, the model and the specific competency, which, in this case, is the SME knowledge management program (Dubois, 2003)). Competency clusters in small and medium-sized enterprises can be seen as an important mechanism for spurring innovation and dynamic economic development. Cluster companies are motivated to compete with one another and it induces their innovativeness. Competency clusters create an environment for innovation and knowledge advancement, which supports the SME knowledge management premise (Tubigi\&Alshawi, 2015). Through competency cluster validation, SME's gain additional benefits that include know-how, cost-saving options, innovative solutions, etc. (Acs, et. al, 2009). Competency clusters intertwine the knowledge management components in order to achieve the effect of synergy in various competencies and improve their performance in the MASK and, thus the SME knowledge management program. The MASK competency cluster model is a productive and innovative improvement tool that not only allows for the transfer of knowledge within the SME, but within the growing competitiveness in their 
Using the Motivation-Attributes-Skills-Knowledge Validation Model in Implementing Knowledge Management Strategies in Small and Midsize Employers (SME'S): A Theoretical Study

target markets (Sorenson, et.al, 2007). The last major factor of the competency cluster relates to the economic advancement, social development, and cultural imprint, as well as by using the model in generating new jobs (Navickas\&Malakauskaitè, 2009). The knowledge management competency cluster enables the association of company specializations belonging to different components of a value chain to promote more extensive cooperation (Sorenson, et.al., 2006). It allows for a more rapid use of knowledge transfer through the ease of access to critical information. The association of these specializations further promotes the collaboration of meeting critical company objectives. This aspect further allows the SME knowledge management program to grow in depth, scope and ease of access. When a SME employs the MASK competency cluster related to developing and advancing its knowledge management, the possibilities to obtain better external resources and increase the capacity to share internal resources with key stakeholder populations is obtained. The competency cluster validation step is a logical capstone to the sequential process contained in the MASK.

Table5. Competency Clusters

\begin{tabular}{|l|l|l|}
\hline \multicolumn{1}{|c|}{ Author } & \multicolumn{1}{|c|}{ Summary } & \multicolumn{1}{|c|}{ Impact on SME's } \\
\hline $\begin{array}{l}\text { Navickas, et.al, } \\
2009\end{array}$ & $\begin{array}{l}\text { SME's tend to utilize their competencies, } \\
\text { reduce various costs, consolidate limited } \\
\text { resources, and hereby increase their } \\
\text { productivity, innovativeness, and profitability. }\end{array}$ & $\begin{array}{l}\text { SMEs may gain additional benefits that } \\
\text { include know-how, cost-saving } \\
\text { options, innovative solutions, etc. }\end{array}$ \\
\hline Irwin, 2008 & $\begin{array}{l}\text { Explores the concept of competencies as a } \\
\text { viable bridge to employer engagement } \\
\text { through three applications: work related skill } \\
\text { sets, standards and professionalism. }\end{array}$ & $\begin{array}{l}\text { By offsetting competencies with } \\
\text { competency clusters, especially related } \\
\text { to quality and vocational competencies } \\
\text { the SME can advance their critical } \\
\text { needs to be successful in their sector. }\end{array}$ \\
\hline $\begin{array}{l}\text { Chanduvi, Lama } \\
\text { \& Morey, 2015 }\end{array}$ & $\begin{array}{l}\text { The studied found grouped in clusters, an } \\
\text { individual's learning is proportional to the } \\
\text { motivation provided to him or her. }\end{array}$ & $\begin{array}{l}\text { It is necessary for SME's to know the } \\
\text { key aspects of each individual in the } \\
\text { formation of competencies that are } \\
\text { grouped into clusters. }\end{array}$ \\
\hline Burgaz, 2008 & $\begin{array}{l}\text { The competitiveness of individuals in the } \\
\text { labor market depends not only on their } \\
\text { vocational competences, but also on whether } \\
\text { they have employability competences and } \\
\text { whether they can continuously develop } \\
\text { them. }\end{array}$ & $\begin{array}{l}\text { SMEs need to raise their awareness of } \\
\text { employability competences so as to } \\
\text { develop a common employability } \\
\text { competences framework to create the } \\
\text { relevant competency clusters the SME } \\
\text { needs to be successful. }\end{array}$ \\
\hline
\end{tabular}

\section{KNOWLEDGe MANAGEMENT}

The focus of the MASK in the development of a knowledge management program within a SME, including the need to illustrate knowledge management, further illustrates the focus of this theoretical study. The successful SME acquires skills during discovery by mimicking success from other SMEs, competitors, employees, suppliers, and customers (Shane, 2000). Knowledge assets are created through exploration or exploitation of specific factors (Mojibi, et. al, 2015). The transfer of preliminary knowledge, whose value is limited due to uncertainty in the SME marketplace, wastes resources as the recipient team responds to incorrect information (Terwiesch,

Loch, De Meyer, 2002). The nature of knowledge management during the evolution of its life cycle focuses on knowledge discovery, to asses SME, to sort and then to knowledge management development. Alternatively, transferring knowledge into an effective knowledge management program too late may delay market impact and effectiveness for the SME. This challenge can cripple SMEs as their ability to quickly seize opportunities often dictates their level of success or survival. Lee at al. (2016), showed that the timing of knowledge transfers is critical to the SME knowledge management program. The timing of knowledge transfer is critical based on the need to get logical, doable, actionable, and timely information in the hands of decision makers at the right time. Further, the decision impact on a SME in more impactful related to knowledge transfer. Ozkan, et al. (2011), argued that knowledge management strategies are needed to maximize the expected total revenue from the development of organizational knowledge and is critical in the transfer of knowledge. Uncertainty can be foreseeable, where the nature of risk is understood, or unforeseeable and characterized by the inability to articulate key drivers of uncertainty related to the knowledge transfer within the SME knowledge management program (Gaimon, \& Bailey, 2013). Developing a 
Using the Motivation-Attributes-Skills-Knowledge Validation Model in Implementing Knowledge Management Strategies in Small and Midsize Employers (SME'S): A Theoretical Study

framework is critical for knowledge transfer for leveraging knowledge management for SME success. In this framework, we describe key knowledge transfer related to SME objectives and capabilities as well as demonstrating the significance of knowledge management as a driver of value. Studies show that in an environment with foreseeable uncertainty and low complexity, the venture's performance is higher using knowledge transfer (Gaimon\& Bailey, 2012). Knowledge transfer encompasses tacit knowledge retained in individuals and structural knowledge, which accumulates due to the codification of tacit knowledge as reflected in routines, procedures, manufacturing processes, and information systems (Tubigi\&Alshawi 2015).

Table6. Knowledge Management

\begin{tabular}{|l|l|l|}
\hline \multicolumn{1}{|c|}{ Author } & \multicolumn{1}{|c|}{ Summary } & \multicolumn{1}{|c|}{ Impact on SME's } \\
\hline Bharadwaj, et al 2016 & $\begin{array}{l}\text { KM is often a function of informal } \\
\text { activities \& is a critical component of } \\
\text { creating a knowledge infrastructure }\end{array}$ & $\begin{array}{l}\text { Comprise creation/acquisition, } \\
\text { storage, dissemination, } \\
\text { and } \\
\text { application }\end{array}$ \\
\hline Brahma \& Mishra, 2015 & $\begin{array}{l}\text { Means for tapping collective intelligence } \\
\text { and skills of employees to create greater } \\
\text { organization knowledge }\end{array}$ & $\begin{array}{l}\text { Develops a collaborative approach } \\
\text { to managing knowledge in a more } \\
\text { focused and agile manner }\end{array}$ \\
\hline $\begin{array}{l}\text { Hoffman, Lopez, \& } \\
\text { Medeiros, 2016 }\end{array}$ & $\begin{array}{l}\text { KM is transferred amongst SME's } \\
\text { operating in industrial clusters along } \\
\text { with KM being multi-dimensional }\end{array}$ & $\begin{array}{l}\text { Allows KM to circulate through a } \\
\text { SME to strengthen the SME's KM } \\
\text { program }\end{array}$ \\
\hline $\begin{array}{l}\text { DiPasquale \&McInerney, } \\
2010\end{array}$ & $\begin{array}{l}\text { Face the same KM issues as large } \\
\text { organizations, but face boundaries in the } \\
\text { development \& implementation of KM } \\
\text { programs }\end{array}$ & $\begin{array}{l}\text { Creates a challenge for SME's to } \\
\text { understand that they need to only add } \\
\text { KM assets that will directly impact } \\
\text { their core competency clusters }\end{array}$ \\
\hline
\end{tabular}

\section{CONCLUSION}

This theoretical study explored the challenges related to managing knowledge management in SME. Through this theoretical study, the illustration of SMEs that participate in clusters can benefit from specialized knowledge management programs, which increases possibilities to expand their markets, which increases the SME's ability to meet the needs of their clients and reduce the cost in producing the service and/or product (Tubigi\&Alshawi, 2015). Within this aspect of the model, the use of the MASK in constructing a SME knowledge management allows the company to develop a more qualified workforce along with encouraging the active knowledge transfer within the SME. The model serves as a natural fit pertaining to the development of knowledge management programs in a SME. The individual components and overall process allows for the various aspects of the program to be de-constructed and then re-constructed, meeting the needs and objectives of the MSE. Navickas\&Malakauskaite (2009), proposed that the productivity of SME knowledge management competency clusters is determined mainly by the following factors:

- The better access to specific information through knowledge transfer.

- Broad supply of knowledge management for the labor force.

- Better access to knowledge management resources.

- Better economies of scale through the knowledge transfer and knowledge management objectives.

- Use of knowledge management benefits to cluster company objectives to complement one another.

The MASK process, in support of SME knowledge management, fosters an entrepreneurial culture by bringing together motivation, attributed skills, and knowledge through the competency cluster model. It also drives resilience to withstand problems and maintain efficiency and sustainability through using the MASK to not only manage knowledge, but also to transfer knowledge. In using the MASK to create a SME knowledge management program, the stakeholders are able to forge links between these populations in a more effective manner. By using the MASK to create a knowledge management program, SMEs can development more productive communications and decisionmaking structures. Through the use of a knowledge management, SMEs tend to minimize their costs 
Using the Motivation-Attributes-Skills-Knowledge Validation Model in Implementing Knowledge Management Strategies in Small and Midsize Employers (SME'S): A Theoretical Study

through specialization of knowledge transfer (Navickas\&Malakauskaite, 2009). The potential for further research is significant as it can be used other SME functions ranging from decision making, to workforce development, or managerial decision making, along with nearly any aspect of business. This model could be further altered to provide expansion and will be the opportunity for SME's, larger enterprises and other entities to implement new and dynamic knowledge management development competency cluster validation models. The potential for future research can be validated through the use of various quantitative experimental designs. As mentioned earlier in this paper, the Critical Incident Technique provided guidance for this theoretical study and would serve a productive methodology for further research in this topical area. Whether future research involves qualitative or quantitative analysis, it is clear that the propositions within this model will serve as productive components in the development of a SME knowledge management program.

\section{APPENDIX A}

\section{Desired Competency Cluster Validation}

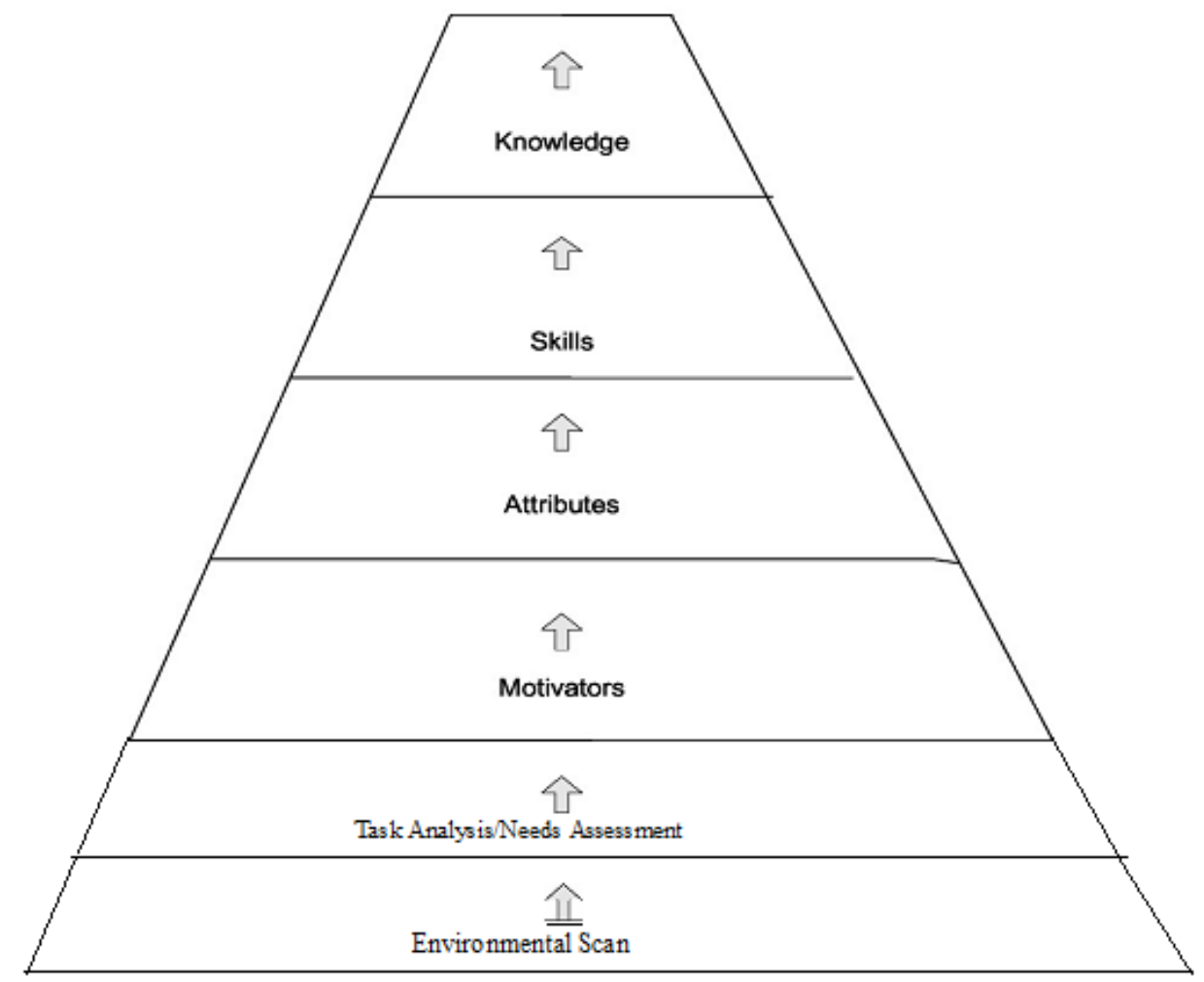

\section{REFERENCES}

[1] Acs, Z.; Braunerhjelm, P.; Audretsch, D..; Carlsson, B. (2009) The knowledge spillover theory of Entrepreneurship. Small Bus. Econ. 32: 15-30.

[2] Argote, L. (1999) Organizational Learning: Creating, Retaining, and Transferring Knowledge. Springer, Dordrecht, The Netherlands.

[3] Arikan, A. (2009) Interfirm Knowledge Exchanges and the Knowledge Exchanges Capability of Clusters. Academy Of Management Review, 34(4), 658. doi:10.5465/AMR.2009.44885776

[4] Baron, R. \& Ensley, M. (2006) Opportunity recognition as the detection of meaningful patterns: Evidence from comparisons of novice and experienced SMEs. Manage. Sci. 52(9): 1331- 1344.

[5] Brahma, S. \& Mishra S. (2016) "Understanding Researchable Issues in Knowledge Management: A Literature Review." IUP Journal of Knowledge Management 13.4 (2015): 43-68. Business Source Complete. Web. 24 Feb. 2016.

[6] Brown, A., Gilbert, B.., Bruno, A.., \& Cooper, G. (2012) Validated competency framework for delivery of pharmacy services in Pacific-Island Countries. Journal of Pharmacy Practice and Research, 42(4), 268.

[7] Bryson, J. (2016) "Putting Skill in Its Place." Journal of Education and Work 28.5 (2015): 551570. ERIC. Web. 26 Feb. 2016. 
Using the Motivation-Attributes-Skills-Knowledge Validation Model in Implementing Knowledge Management Strategies in Small and Midsize Employers (SME'S): A Theoretical Study

[8] Cao, Q., Thompson, M. A., \&Triche, J. (2013). Investigating the role of business processes and knowledge management systems on performance: A multi-case study approach. International Journal Of Production Research, 51(18), 5565-5575. doi:10.1080/00207543.2013.789145

[9] Chatterjee, S. (2014). Managing Constraints and Removing Obstacles to knowledge management. IUP Journal Of Knowledge Management, 12(4), 24-38.

[10] Cohen, W. \& Levinthal, D. (1990) Absorptive capacity: A new perspective on learning and innovation. Administrative Science Quarterly. 35 (1): 128-152.

[11] Cope, J. 2005. Toward a dynamic learning perspective of Entrepreneurship. Entrepreneurship Theory and Practice 29(4): 373-397.

[12] DiPasquale, J. \&McInerney, C. (2010) "Knowledge Management in Small- And Medium-Sized Enterprises." Journal of Information \& Knowledge Management 9.4: 341-353. Library, Information Science \& Technology Abstracts with Full Text. Web. 25 Feb. 2016.

[13] Dubois, D. (1993) Competency-Based Performance Improvement: A Strategy for Organizational Development. New York: Simon \& Schuster.

[14] Gaimon, C. \& Bailey, J. (2013) Knowledge Management for the Entrepreneurial Venture. Production \& Operations Management, 22(6), 1429-1438. doi:10.1111/j.19375956.2012.01337.x

[15] Gonzalez, R. \& Martins, M. (2014) Knowledge Management: an Analysis from the Organizational Development. Journal of Technology Management \& Innovation, 9(1), 131-147.

[16] Hauser, L. (2014) Work motivation in organizational behavior. Economics, Management \& Financial Markets, 9(4), 239-246.

[17] Hetzner, S Heid H. \& Gruber, H. (2016) "Using Workplace Changes As Learning

[18] Opportunities: Antecedents To Reflection In Professional Work." Journal Of Workplace Learning 27.1 (2015): 34-50. ERIC. Web. 26 Feb. 2016.

[19] Irwin, P. (2008) "Competencies and Employer Engagement." Asia Pacific Education Review9.1(2008): 63-69.

[20] Jain, A. \& Moreno, A. (2015). Organizational learning, knowledge management practices and firm's performance. Learning Organization, 22(1), 14-39. Doi: 10.1108/TLO-05-20130024

[21] Lee, P., To, K. \& Yu B. (2016) "Team Attributes and Performance of Operational Service

[22] Teams: An Empirical Taxonomy Development." International Journal of Production Economics 142.1 (2013): 51-60. Business Source Complete. Web. 26 Feb. 2016.

[23] Lippert, R., \&Gaáil, Z. (2014) Management Approach between Business Cluster Success and Soft Leader Characteristics. Problems of Management in the 21St Century, 9(1), 27-34.

[24] Mojibi, T., Khojasteh, Y., \&Khojasteh-Ghamari, M. (2015) The Role of Infrastructure Factors in Knowledge Management Implementation. Knowledge \& Process Management, 22(1), 34-40. Published online 28 January 2015 in Wiley Online Library (www.wileyonlinelibrary.com) DOI: 10.1002/kpm.1459 doi: $10.1002 / \mathrm{kpm}$.

[25] Navickas, V., \&Malakauskaitè, A. (2009). The impact of clusterization on the development of and medium-sized enterprise (SEM) Sector. Journal of Business Economics \&Management, 10(3), 255-259. doi:10.3846/1611-1699.2009.10.255-259

[26] Prasad, S. \& Tran, H. (2016) "Work Practices, Incentives for Skills, And Training." Labour Economics 23. (2013): 66-76. Science Direct. Web. 26 Feb. 2016.

[27] Shea-Van Fossen, R. \&Vredenburgh, D (2014) Exploring Differences in Work's Meaning: An Investigation of Individual Attributes Associated with Work Orientations. Journal of Behavioral \& Applied Management, 15(2), 101-120.

[28] Shane, S. 2000. Prior knowledge and the discovery of Entrepreneurial opportunities. Organ. Sci. 11(4): 448-469.

[29] Shane, S., \& Eckhardt, J. (2005) The individual-opportunity nexus. In Z. J. Acs, \& D. B. Audretsch (Eds.), Handbook of Entrepreneurship Research: An Interdisciplinary Survey and Introduction (pp. 161-191). New York, NY: Springer.

[30] Sorenson, O., Rivkin, J. \& Fleming, L. (2006) Complexity, networks, and knowledge flow. Res. Policy 35 : 994-1017.

[31] Stevens, Jeff (2005). Competency Cluster Validation Model an Empirical Study. Journal of American Academy Of Business, Cambridge, 6(2), 264-272.

[32] Stevens, Jeff (2011). Competency cluster validation model: An empirical study of management" Journal of Information Systems Technology and Planning-JISTP, 4(8) 
Using the Motivation-Attributes-Skills-Knowledge Validation Model in Implementing Knowledge Management Strategies in Small and Midsize Employers (SME'S): A Theoretical Study

[33] Taylor, Beverley M. "The Integrated Dynamics of Motivation and Performance In The Workplace." Performance Improvement 54.5 (2015): 28-37. Business Source Complete. Web. 26 Feb. 2016.

[34] Terwiesch, C., Loch, C., \& De Meyer, A. (2002) Exchanging preliminary information in concurrent engineering: Alternative coordination strategies. Organ. Sci. 13: 402-419.

[35] Tubigi, M. \&Alshawi, S. (2015). The impact of knowledge management processes on organization performance. Journal of Enterprise Information Management, 28(2), 167185. Doi: 10.1108/JEIM-012014-0003

[36] Vivas, C.; Sobreiro, P. \&Claudino, R. (2016) "Integrating Knowledge Management in a Business Strategy Process Operationalized Using Process Management Approach." Proceedings of the European Conference on Knowledge Management 3. (2014): 10451054. Library, Information Science \& Technology Abstracts with Full Text. Web. 1 Mar. 2016.

[37] Ward, T. (2004) Cognition, creativity and Entrepreneurship. Journal of Business Venturing 19(2): 173188.

[38] Wiklund, J. \& Shepherd, D. (2003) Knowledge based resources, Entrepreneurial orientation, and the performance of small and medium sized businesses. Strategic Management Journal 24(13): 1307-1314.

Citation: Jeff Stevens, PhD, Jim Chen, PhD. “ Using the Motivation-Attributes-Skills-Knowledge Validation Model in Implementing Knowledge Management Strategies in Small and Midsize Employers (SME'S): A Theoretical Study" International Journal of Managerial Studies and Research (IJMSR), vol 6, no. 7, 2018 , pp. 20-33. doi:http://dx.doi.org/10.20431/2349-0349.0607003.

Copyright: (c) 2018 Authors. This is an open-access article distributed under the terms of the Creative Commons Attribution License, which permits unrestricted use, distribution, and reproduction in any medium, provided the original author and source are credited. 